Article

\title{
Fatigue Performance of Tunnel Invert in Newly Designed Heavy Haul Railway Tunnel
}

\author{
Cong Liu ${ }^{1,2}$, Limin Peng ${ }^{1}$, Mingfeng Lei ${ }^{1,3, * \mathbb{C}}$, Chenghua Shi ${ }^{1}$ and Ning Liu ${ }^{1,2}$ \\ 1 School of Civil Engineering, Central South University, Changsha 410075, China; \\ liucong731@csu.edu.cn (C.L.); lmpeng@csu.edu.cn (L.P.); csusch@163.com (C.S.); nliu1@gzu.edu.cn (N.L.) \\ 2 School of Civil Engineering, Guizhou University, Guiyang 550025, China \\ 3 Key Laboratory of Engineering Structure of Heavy Haul Railway (Central South University), \\ Changsha 410075, China \\ * Correspondence: mingdfenglei@csu.edu.cn
}

Received: 22 November 2019; Accepted: 12 December 2019; Published: 14 December 2019

check for updates

\begin{abstract}
The Haoji railway in China is the longest heavy haul railway in the world, including 235 tunnels located along the $1837 \mathrm{~km}$ railway. With the increasing axle load of the new line and the basal deterioration of the existing heavy haul railway in China, studying the fatigue performance of the newly designed tunnel structure is essential. To study the coupling effect of the surrounding rock pressure and $30 \mathrm{t}$ axle load train, in this study, we combined three-dimensional numerical simulation and three-point bending fatigue tests to investigate the fatigue performance of the basal structures. The results of numerical simulation indicate that the center of the inverted arch secondary lining is the position vulnerable to fatigue in the lower tunnel structures; the surrounding rock pressure performance exerts a stronger influence on the stress state of the vulnerable position than the dynamic train loads. The $S-N$ formula obtained from the experiment showed that the fatigue life of tunnel bottom structures decreases with increasing surrounding rock pressure and dynamic load. In typical grade $\mathrm{V}$ surrounding rock and $30 \mathrm{t}$ axle loads, fatigue failure will not occur in the newly designed tunnel bottom structures within 100 years if bedrock defects are lacking and pressure of surrounding rock is not excessive.
\end{abstract}

Keywords: heavy haul; railway tunnel; bottom structure; fatigue

\section{Introduction}

Researchers reported that fatigue would not occur in the tunnel basal structures. Rickstal et al. [1] conducted a series of fatigue tests based on the measured vehicle loads in highway tunnels, and the results revealed that the floor was still intact after 6 million cycles. Through scale model tests, Wang et al. [2] stated that fatigue failure of tunnel bottom structures would not occur under the long-term action of a high-speed train. Han et al. [3] and Qian et al. [4] indicated that segments of the shield tunnel bottom would be stable for the designed service life (100 years) using fatigue tests.

The increase in train axle load can considerably increase the railway's capacity and efficiency and reduce the transportation cost per unit freight [5]; however, tunnel basal degradation increases with increasing axle load and operation period [6]. For example, the Daqin heavy haul railway has the world's highest annual freight volume (445 million tons in 2013 [7]). After more than 20 years of operation, basal deterioration is increasing over time in many tunnels, and most basal deterioration is appearing on the side of the full load track [8], which decreases the operational safety. Serious foundation subsidence and base rock voids have been found below the full load track in the Jundushan Tunnel along the Daqin railway [9]. Severe basal deterioration has also emerged along another heavy haul railway, the Shuohuang railway, including basement subsidence and rising soil on the side of the 
full load track, as observed in the Shuiquanwan and Daping tunnels, where the maximum settlement is $1.5 \mathrm{~cm}$ in the Shuiquanwan tunnel $[8,10]$.

To study the mechanism of basal degradation and the fatigue performance of the base structure of heavy haul railway tunnels, through numerical simulation, Xue [11] indicated that a loose basement leads to a significant increase in the maximum tensile stress of the inverted arch filling (IAF) and fatigue damage would occur under the long-term operation of a $30 \mathrm{t} /$ axle load heavy haul train. Based on a fatigue test, Liu et al. [12] also found that the lower the stiffness of the basement, the faster the development of the fatigue damage of tunnel inverted arches. Zhang et al. [13] stated that when a void exists in the base, the displacement and maximum principal stress of the tunnel bottom structure caused by train load increase significantly; then, based on the existing $S-N$ curve of concrete tension fatigue, the calculation suggested that the fatigue life of the tunnel bottom structure is less than 100 years when the basal void is $\geq 2 \mathrm{~m}$.

The fatigue performance of a structure is not only affected by the dynamic load, but also by the static load [14]. Under the same dynamic load, the fatigue life decreases with increasing static load. Stresses of tunnel bottom structures include the dynamic stress caused by the train load and the static stress caused by surrounding rock pressure. Existing research on fatigue performance of a railway tunnel has mainly focused on the influence of dynamic stress [1-4]; the influence of surrounding rock pressure on the fatigue performance of the tunnel bottom structure needs further study, especially in shallow buried weak surrounding rock with high surrounding rock pressure.

The Haoji railway in China is newly designed and the longest heavy haul railway in the world, with 235 tunnels located along the $1837 \mathrm{~km}$ railway. According to a survey, basal deterioration has appeared in many existing heavy haul railway tunnels, so analyzing the fatigue of the new line's basal structures that are experiencing higher axle load and freight volume is essential.

In the investigation described in this paper, three-dimensional (3D) numerical simulation and three-point bending fatigue tests were combined to investigate the fatigue performance of tunnel bottom structures along the new line. The stress state of the most unfavorable position of the tunnel invert was determined using numerical simulation, and the static stress caused by the surrounding rock pressure and the dynamic stress caused by the train were identified. The fatigue test condition was then designed according to the stress state of the most unfavorable position to identify the fatigue lives of the specimens under different stress states. This paper studies the fatigue performance of a heavy haul railway tunnel under the action of high surrounding rock pressure and large axle load train and provides a reference for the durability design of heavy haul railway tunnel structures.

\section{Mechanical Characteristics of the Heavy Haul Railway Tunnel Base}

\subsection{Engineering Background}

The designed axle load of the Haoji heavy haul railway is $30 \mathrm{t}$ and the annual freight volume is 200 million $\mathrm{t}$, so about 2 million trains will travel along the railway in the 100 years of designed service life. The typical section diagram of the Haoji railway tunnel in grade V surrounding rock (Grade I is the best, grade VI is the worst) [15] is shown in Figure 1. The tunnel is $1152 \mathrm{~cm}$ high and $1145 \mathrm{~cm}$ wide.

\subsection{Numerical Model}

Based on Figure 1, a refined numerical train-track-tunnel model was established by using finite element modeling (FEM) software ABAQUS (Dassault Simulia, Providence, RI, USA). The model size was $100 \mathrm{~m}$ wide, $100 \mathrm{~m}$ tall, and $30 \mathrm{~m}$ long. Forming a ground arch in a shallow tunnel is difficult, and, as a result, in general, its structural stress is more unfavorable compared to a deep tunnel [16], so the distance between the tunnel vault and the ground surface was set to $15 \mathrm{~m}$ [17]. The system anchor bolt was ignored in this model due to its limited effect in shallow tunnels. The tunnel lining, inverted arch filling, track plate base, flexible cushion, track plate, sleeper, rail wheel, boogie, and train wagon were all elastic materials; the surrounding rock was elastoplastic material; and C3D8R solid 
elements were adopted to simulate these components. We used a total of 187,822 elements for this mesh. The train-track-tunnel integrated model and its mesh are presented in Figure 2.

Fixed boundary constraints were adopted on the sides of the model. The normal stiffness of the viscoelastic boundary [18] was $2.5 \times 10^{6} \mathrm{~N} / \mathrm{m}$, normal damping was $1.29 \times 10^{6} \mathrm{~kg} \cdot \mathrm{m}^{-2} \cdot \mathrm{s}^{-1}$, shear stiffness was $5.0 \times 10^{6} \mathrm{~N} / \mathrm{m}$, and shear damping was $6.35 \times 10^{6} \mathrm{~kg} \cdot \mathrm{m}^{-2} \cdot \mathrm{s}^{-1}$.

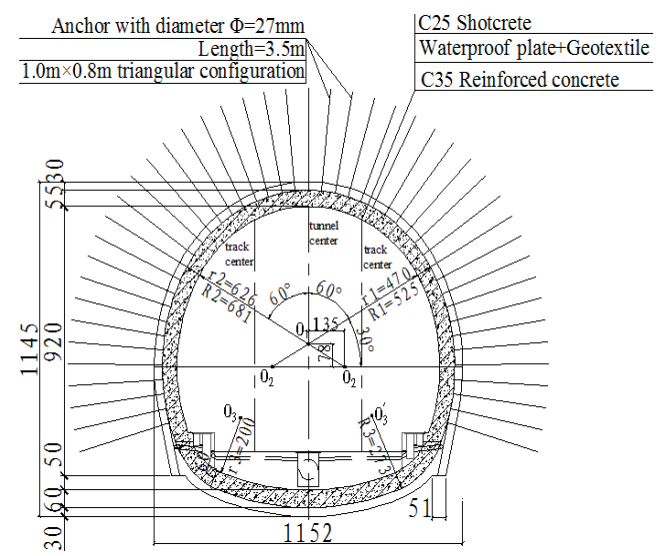

Figure 1. Section structure of the heavy haul railway tunnel in grade V surrounding rock $(\mathrm{cm})$.

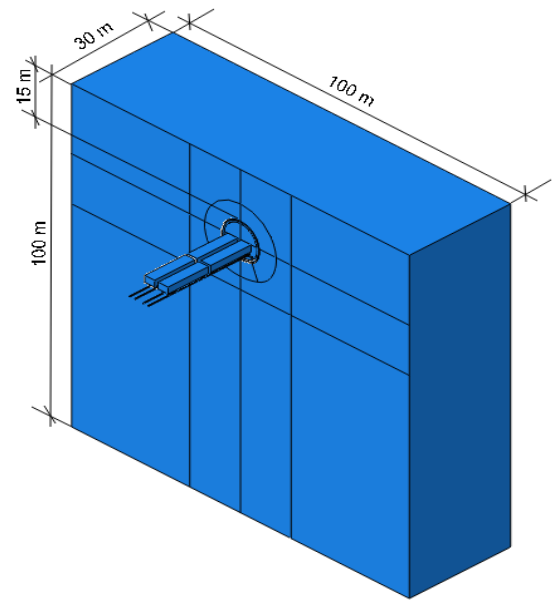

(a)

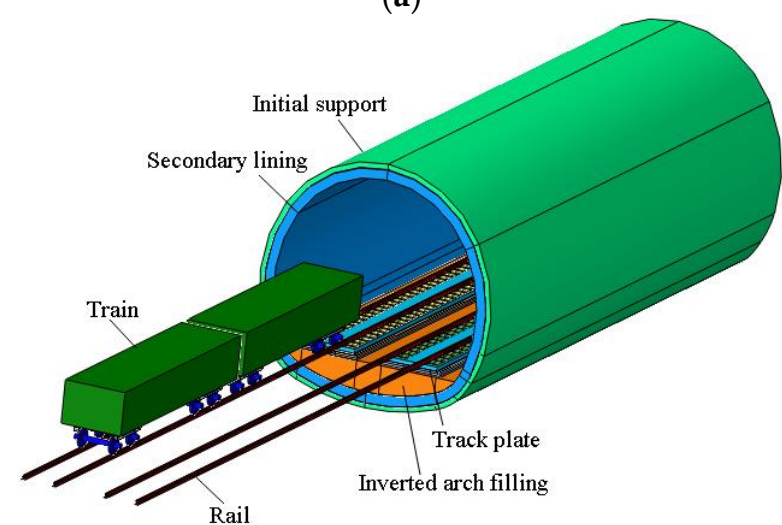

(b)

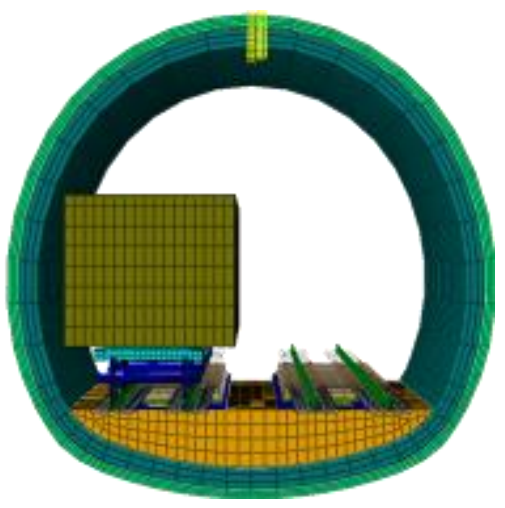

(c)

Figure 2. Numerical model of train-track-tunnel coupling system: (a) Model size; (b) structure of the model; and (c) mesh of numerical model. 
The mechanical parameters of the model materials were selected from the Chinese standard [19] and are listed in Table 1.

Table 1. Mechanical parameters.

\begin{tabular}{|c|c|c|c|c|c|}
\hline Material & $\begin{array}{l}\text { Density } \\
\left(\rho / \mathrm{kg} / \mathrm{m}^{3}\right)\end{array}$ & $\begin{array}{c}\text { Elastic Modulus } \\
E(\mathrm{GPa})\end{array}$ & $\begin{array}{l}\text { Poisson } \\
\text { Ratio } \mu\end{array}$ & $\begin{array}{c}\text { Tensile Strength } \\
f_{t}(\mathrm{MPa})\end{array}$ & $\begin{array}{c}\text { Compressive Strength } \\
f_{c}(\mathrm{MPa})\end{array}$ \\
\hline Secondary lining (C35) & 2600 & 31.5 & 0.2 & 2.20 & 23.4 \\
\hline Inverted arch filling (C25) & 2500 & 19.8 & 0.3 & 1.78 & 16.7 \\
\hline Foundation plate (C30) & 2500 & 30 & 0.2 & 2.01 & 20.1 \\
\hline Flexible cushion (C30) & 2200 & 20 & 0.2 & 2.01 & 20.1 \\
\hline Material & $\begin{array}{l}\text { Density } \\
\left(\rho / \mathrm{kg} / \mathrm{m}^{3}\right)\end{array}$ & $\begin{array}{c}\text { Elastic modulus } \\
E(\mathrm{GPa})\end{array}$ & $\begin{array}{l}\text { Poisson } \\
\text { Ratio } \mu\end{array}$ & $\begin{array}{l}\text { Cohesion } \\
c(\mathbf{k P a})\end{array}$ & $\begin{array}{l}\text { Internal Friction Angle } \\
\varphi\left(\left(^{\circ}\right)\right.\end{array}$ \\
\hline V grade surrounding rock & 2100 & 0.50 & 0.33 & 80 & 25 \\
\hline
\end{tabular}

The contact relationships are shown in Figure 3; the constraints between the wheel, bogie, and train wagon are rigid bodies. The tie constraints were used to simulate the relationship between other components of the model, such as rocks and initial support, initial support and secondary lining, filling layer and track plate, and sleeper and track plate.

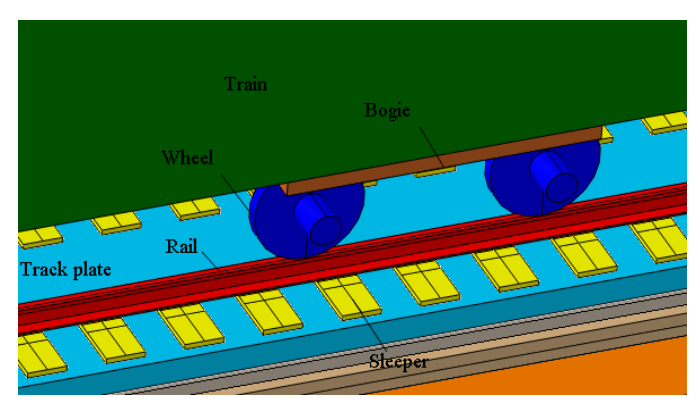

Figure 3. Wheel-rail contact.

Surface-to-surface contact was adopted to simulate the relationship between wheel and track; the wheel was the predominant surface and the normal force between the wheel and the track was determined using Hertz nonlinear elastic contact theory [20], as shown in Equation (1):

$$
P_{N}(\mathrm{t})=\left[\frac{1}{G} \delta N(t)\right]^{3 / 2}
$$

where $P_{N}(\mathrm{t})$ is the wheel/rail normal force $(\mathrm{N}), \delta N(t)$ is the normal elastic compression of the wheel/rail contact point, $t$ is the running time of the model, $G$ is the constant for wheel/rail contact, LM is the wear type tread $G=3.86 R^{-0.115} \times 10^{-3}\left(\mathrm{~m} / \mathrm{N}^{2 / 3}\right)$, and $R$ is the wheel rolling radius (m).

The train axle load was $30 \mathrm{t}$, the Cartesian connector was adopted to simulate the relationship between track and sleeper, and the parameters are provided in Table 2.

Table 2. Spring stiffness and damping parameters of the $30 \mathrm{t}$ axle load train.

\begin{tabular}{ccccc}
\hline Position & \multicolumn{3}{c}{ Stiffness Coefficient $(\mathbf{M N} / \mathbf{m})$} & Damping (kN·s/m) \\
\cline { 2 - 5 } & $k_{x}$ & $k_{y}$ & $k_{z}$ & $c_{z}$ \\
\hline $\begin{array}{c}\text { Primary } \\
\text { suspension }\end{array}$ & 6.0 & 10.0 & 35.0 & 5.0 \\
$\begin{array}{c}\text { Secondary } \\
\text { suspension }\end{array}$ & 5.3 & 5.3 & 6.6 & 5.0 \\
\hline
\end{tabular}




\subsection{Feature Points and Feature Lines}

For tunnels, the inverted arch secondary lining (IASL) is the most important barrier for the safety of tunnel bottom structures. As long as the IASL does not crack, mud and water will not flow into the tunnel. This paper mainly focuses on the stress state and fatigue performance of the IASL. So, the feature points and feature lines were arranged, as shown in Figure 4.

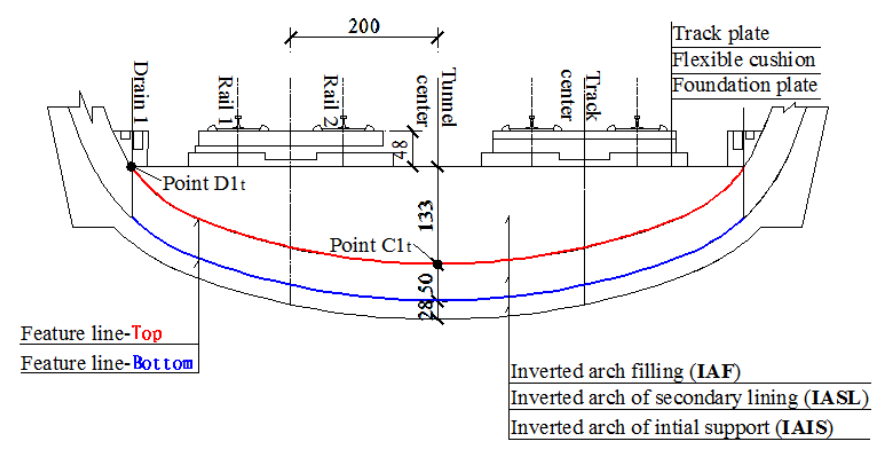

Figure 4. Layout of feature points and lines (cm).

\section{Mechanical Characteristics}

The maximum principal strain was selected to illustrate the stress state of the IASL (Figure 5) because it was easy to acquire during the fatigue tests, facilitating a results comparison between the calculation and tests.

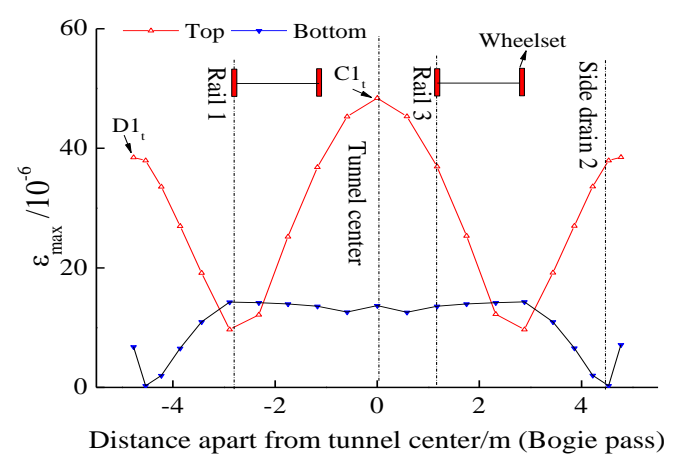

(a)

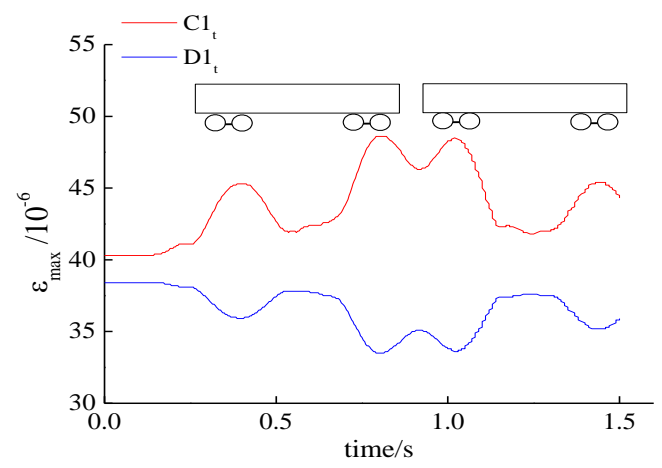

(b)

Figure 5. Maximum principal strain of inverted arch secondary lining: (a) Horizontal distribution and (b) time-history curve.

When two $30 \mathrm{t}$ axle load carriages pass through a tunnel, the tunnel experiences the coupled action of surrounding rock pressure and dynamic train load. Figure 5a shows that the maximum principal strain is located at point $\mathrm{C} 1_{t}$, the top center of the IASL. The maximum principal strain of $R 2_{t}$ and $\mathrm{D} 1_{t}$ is also relatively large. Figure $5 \mathrm{~b}$ indicates that peak strain occurs when a wheel set passes, and the maximum principal strain appears when the bogie passes $(0.80 \mathrm{~s}, 1.02 \mathrm{~s})$. The $\varepsilon_{\max }$ of point $C 1_{t}$ is $48.6 \times 10^{-6}$ and that of point $C 1_{t}$ is $8.3 \times 10^{-6}$. This illustrates that the influence of the surrounding rock pressure is stronger than the dynamic train load on the stress state of IASL; the vulnerable position is under a high static and low dynamic stress state.

The time-history curve reveals that when a train passes through a tunnel, two types of dynamic impact occur: The first and last wheel sets of the train are separate wheel set impacts, while all carriages in the middle are impacted by bogies (two sets of adjacent wheel sets). The maximum stress cycle only occurs once, but hundreds of small stress cycles occur simultaneously. 


\section{Fatigue Test of Tunnel Base Structures}

The results of numerical simulation revealed that under the action of surrounding rock pressure (V), the static strain of the most unfavorable position was $40.3 \times 10^{-6}$, and its dynamic strain caused by the train load (30 t) was $8.3 \times 10^{-6}$. The strain caused by the surrounding rock pressure was far greater than that caused by the train load. According to the high static and low dynamic stress state, a set of bending fatigue test systems and a series of test conditions were designed to study the fatigue lives of the specimens under different stress states.

\subsection{Fatigue Test System}

The top center of the IASL is the most vulnerable position in the tunnel bottom. According to the high static and low dynamic bilateral confinement stress state, a fatigue test system was designed to study the bending fatigue performance of the heavy haul railway tunnel, as shown in Figure 6.

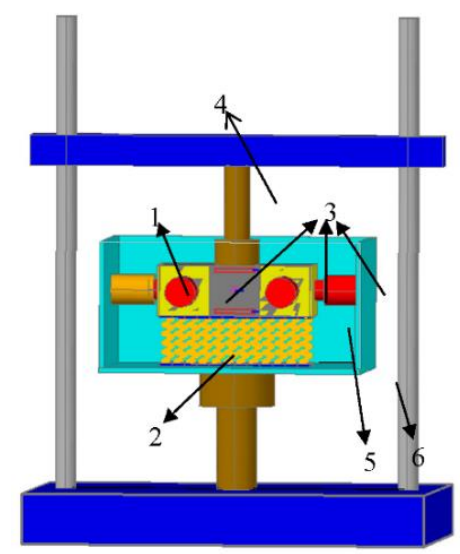

Figure 6. Fatigue test system. 1. Side support; 2. bottom spring; 3. digital hydraulic jack; 4. MTS (Mechanical Testing and Sensing) system; 5 . contact steel plate; 6 . model box.

The test box size was $400 \times 300 \times 250 \mathrm{~mm}$. The bedrock was not completely rigid, the elastic resistance coefficient of V-grade surrounding rock was $193.5 \mathrm{MPa} / \mathrm{m} \mathrm{[15],} \mathrm{and} \mathrm{the} \mathrm{interaction} \mathrm{between}$ the bedrock and the inverted arch specimen was simulated using 27 uniformly distributed springs. The equivalent spring stiffness was $215 \mathrm{kN} / \mathrm{m}$. The bilateral horizontal forces of the specimen were applied using digital hydraulic jacks (No. 3 in Figure 6) and the vertical load of the specimen was applied using MTS815 (No. 4 in Figure 6) (MTS system Co., Eden Prairie, MN, USA).

The concrete (C35) composition of the test specimens is provided in Table 3.

Table 3. Concrete composition.

\begin{tabular}{ccccccc}
\hline Material & Cement & Fine Aggregate & Coarse Aggregate & Fly Ash & Plasticizer & Water \\
\hline $\mathrm{kg} / \mathrm{m}^{3}$ & 277 & 747 & 1075 & 108 & 3.85 & 153 \\
\hline
\end{tabular}

The mechanical parameters of the specimens are shown in Table 4. Cube specimens were used to reflect the static elastic modulus and compressive strength of the C35 concrete, and rectangular specimens were used to reflect its dynamic elastic modulus and bending strength. The ultimate bending strength of the specimens was $2.5 \mathrm{MPa}$, and the corresponding peak load was $40 \mathrm{kN}$ (mean value) when the specimens cracked. 
Table 4. Mechanical parameters of specimens.

\begin{tabular}{|c|c|c|c|c|c|}
\hline \multirow{2}{*}{$\begin{array}{l}\text { Mechanical } \\
\text { Parameters }\end{array}$} & \multicolumn{2}{|c|}{$\begin{array}{l}\text { Cube Specimens } \\
150 \times 150 \times 150 \mathrm{~mm}\end{array}$} & \multicolumn{3}{|c|}{$\begin{array}{l}\text { Rectangular Specimens } \\
100 \times 100 \times 300 \mathrm{~mm}\end{array}$} \\
\hline & $\begin{array}{c}\text { Static Elastic } \\
\text { Modulus } E(\mathrm{GPa})\end{array}$ & $\begin{array}{l}\text { Compression } \\
\text { Strength (MPa) }\end{array}$ & $\begin{array}{l}\text { Dynamic Elastic } \\
\text { Modulus E (GPa) }\end{array}$ & $\begin{array}{l}\text { Bending Strength } \\
(\mathrm{MPa})\end{array}$ & Poisson Ratio $v$ \\
\hline Value & 21.7 & 42.3 & 31.8 & 2.5 & 0.23 \\
\hline
\end{tabular}

\subsection{Load Condition}

The fatigue performance was influenced by maximum tensile stress, dynamic tensile stress, and ultimate flexural strength. The variable of stress level $S$ was introduced to reduce the parameters of the $S-N$ formula.

The definition equations are presented in Equations (2)-(4):

$$
\begin{gathered}
S_{\min }=\sigma_{\min } / f_{t}=F_{\min } / F_{t} \\
\Delta S=\left(\sigma_{\max }-\sigma_{\min }\right) / f_{t}=\left(F_{\max }-F_{\min }\right) / F_{t}=\Delta F / F_{t} \\
S_{\max }=\sigma_{\max } / f_{t}=F_{\max } / F_{t}
\end{gathered}
$$

where $S_{\min }$ is the minimum stress/load level or static stress/load level, $S_{\max }$ is the maximum stress/load level or static stress/load level, $\Delta S$ is the dynamic stress/load level, $\sigma_{\min }$ is the tensile stress caused by the surrounding rock pressure, $\sigma_{\max }$ is the tensile stress caused by the coupling load, $F_{\min }$ is the minimum value of the fatigue load, $F_{\max }$ is the maximum value of the fatigue load, $\Delta F$ is the dynamic load of the fatigue load, and $f_{t}$ is the ultimate flexural strength of the specimen.

The fatigue load was simplified to a sinusoidal wave, as indicated in Figure 7. We applied 1.5 MPa lateral confining stress using the lateral hydraulic jack.

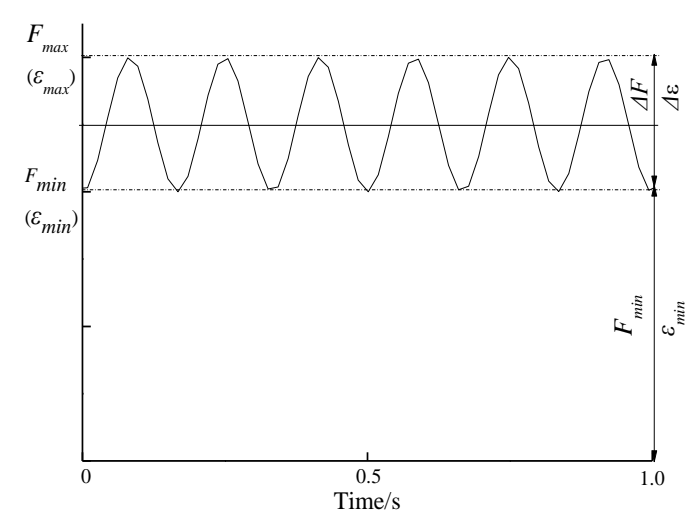

Figure 7. Sketch map of simplified cyclic loading.

The numerical simulation and the specimen strength test conditions are outlined in Table 5. The test was terminated when a fracture occurred in the specimen; the number of cycles was recorded as the fatigue life of the specimen. If no fracture occurred after 2 million cycles, the test was terminated. The mechanical properties of plain concrete specimens were discrete, so every test condition was conducted in triplicate. 
Table 5. Test conditions.

\begin{tabular}{ccccc}
\hline \multicolumn{2}{c}{ Test Conditions } & Constant Loads & Dynamic Load (kN) & $S_{\max }$ \\
\hline \multirow{3}{*}{$\begin{array}{c}\text { Dynamic load } \\
\text { conditions }\end{array}$} & Case 1 & Static load: 27 kN & 1.6 & 0.65 \\
& Case 2 & Lateral load: 1.5 & 2.4 & 0.70 \\
& Case 3 & $\mathrm{kN}$ & 3.6 & 0.75 \\
& Case 4 & & 4.5 & 0.80 \\
\hline \multicolumn{2}{c}{ Test conditions } & Constant loads & Static load (kN) & $S_{\max }$ \\
\hline \multirow{2}{*}{ Static load } & Case 5 & Dynamic load: 2.4 & 23 & 0.60 \\
conditions & Case 6 & kN & 25 & 0.65 \\
& Case 7 & Lateral load: 1.5 & 27 & 0.70 \\
& Case 8 & $\mathrm{kN}$ & 29 & 0.80 \\
\hline
\end{tabular}

Bilateral loads in all test conditions were $1.5 \mathrm{kN}$ to reflect the horizontal confinement of the tunnel invert specimens. In dynamic load conditions (case 1-4), the static loads were the same and represented that the tunnel was under the same surrounding rock pressure and the dynamic loads were different to investigate the influence of the different axle load train. In static load conditions (case 5-8), the dynamic loads were the same and represented that the tunnel is under the action of the same axle load train and the static loads were different to study the influence of the different pressure of the surrounding rock.

\subsection{Sensor Layout}

Two strain gauges (length: $80 \mathrm{~mm}$, resistance: $120 \Omega$ ) were attached to the side of the specimen, both located on the middle section of the specimen, and the specimen's failure was controlled by the tensile strain (sensor 2\#). The sensor layout is shown in Figure 8. The strain was acquired using an IMC dynamic strain acquisition instrument (Integrated Measurement \& Control Co., Berlin, Germany).

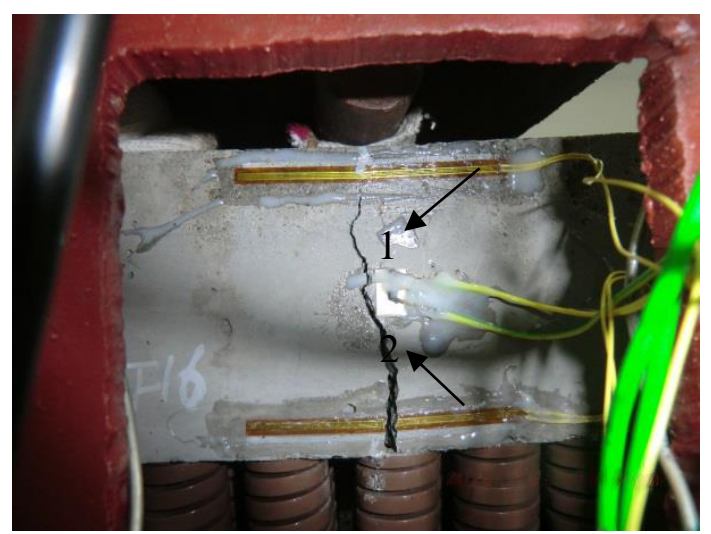

Figure 8. Layout of strain gauges: 1 . Compression strain gauge (top center); 2 . tensile strain gauge (bottom center).

\subsection{Strain Evolution}

The maximum strain evolutions of the specimens are illustrated in Figure 9. We found that the maximum tensile strain increased with $N$ and the fatigue life decreased as the dynamic load and static load increased. When $S_{\max } \leq 0.65\left(\varepsilon_{\max } \leq 56 \times 10^{-6}, \Delta \varepsilon \leq 16 \times 10^{-6}\right)$, the specimens were still intact after 2 million cycles and the maximum tensile strains developed in two stages. When $S_{\max } \geq 0.7\left(\varepsilon_{\max } \geq 68 \times 10^{-6}, \Delta \varepsilon \geq 28 \times 10^{-6}\right)$, the maximum tensile strain of the specimens developed in three stages. 


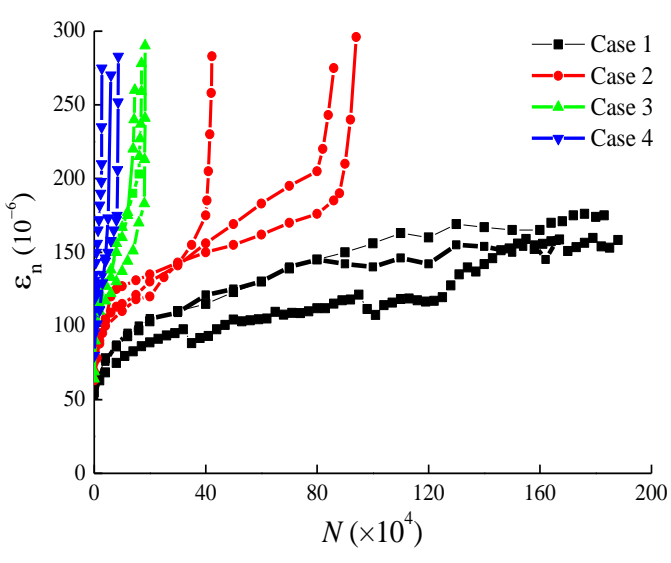

(a)

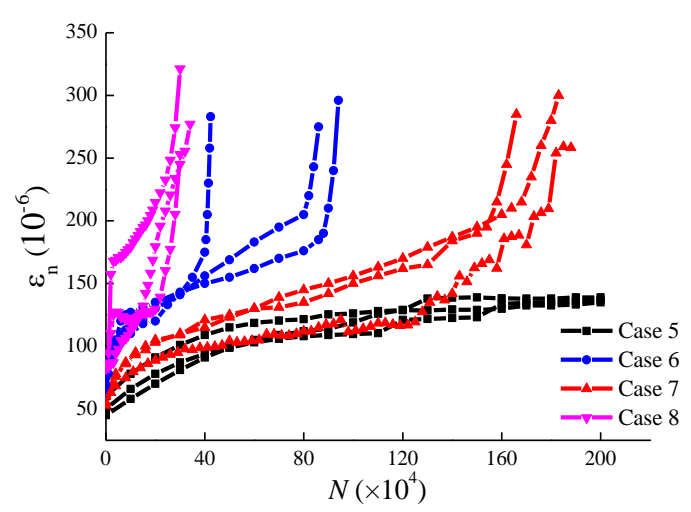

(b)

Figure 9. $\varepsilon_{\mathrm{n}}-N$ curves: (a) Dynamic and (b) static cases.

An S-shaped model was introduced to describe the characteristics of the three-stage strain evolution under the abscissa of $N / N_{f}$ (Figure 10). The model is expressed by Equation (5) and its parameters are listed in Table 6. Figure 10 shows that the maximum tensile strain increased rapidly in stage I due to the increase in microcracks [21]; in stage II, the maximum tensile strain increased steadily and linearly as a result of stable crack growth; in stage III, the maximum tensile strain increased sharply and nonlinearly due to an unstable crack growth. The transition of stages have been specified by different authors in the range of 10 to $20 \%$ (first transition) and about 80 to $90 \%$ (second transition) of the number of cycles to failure [22].

$$
\frac{\varepsilon_{n}}{\varepsilon_{0}}=\lambda+\alpha\left(\frac{\beta}{\beta-N / N_{f}}-1\right)^{\gamma}
$$

where $\varepsilon_{n}$ is the maximum tensile strain of the specimen after $N$ cycles, $\varepsilon_{0}$ is the maximum tensile strain during the first cycle, and $\lambda, \alpha, \beta$, and $\gamma$ are the fitting parameters of the curve.

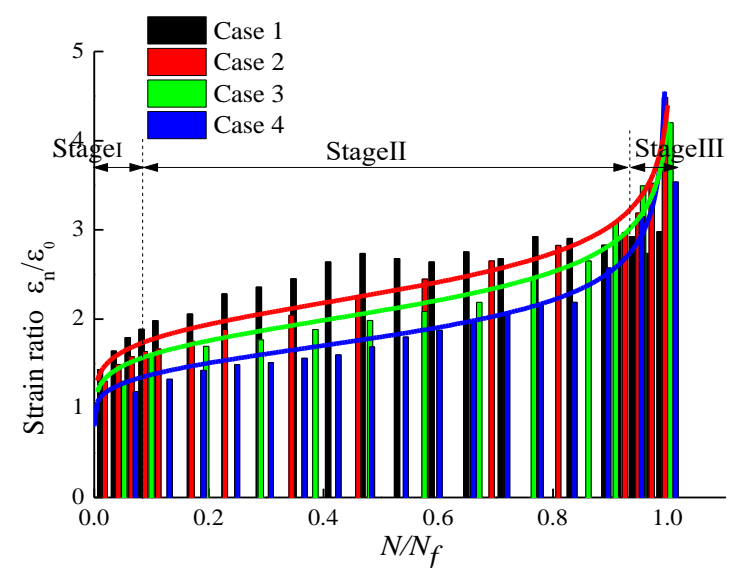

(a)

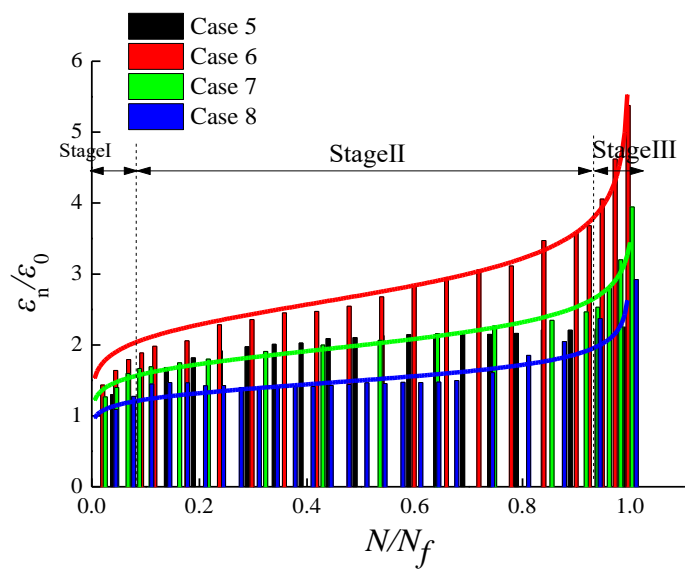

(b)

Figure 10. $\varepsilon_{\mathrm{n}} / \varepsilon_{0}-N / N_{f}$ curves: (a) Dynamic and (b) static cases. 
Table 6. Fitting parameters.

\begin{tabular}{cccccccccc}
\hline Case & $\lambda$ & $\alpha$ & $\boldsymbol{\beta}$ & $\boldsymbol{\gamma}$ & Case & $\boldsymbol{\lambda}$ & $\boldsymbol{\alpha}$ & $\boldsymbol{\beta}$ & $\boldsymbol{\gamma}$ \\
\hline 2 & 0.7 & 1.5 & 1.01 & 0.18 & 6 & 0.7 & 2 & 1 & 0.17 \\
3 & 0.7 & 1.4 & 1.01 & 0.2 & 7 & 0.6 & 1.4 & 1.01 & 0.15 \\
4 & 0.8 & 1 & 1 & 0.25 & 8 & 0.5 & 1 & 1 & 0.14 \\
\hline
\end{tabular}

\subsection{Fatigue Performance of Tunnel Basal Structures}

Based on the fatigue lives of specimens in Table 7, a two-parameter fatigue life $(S-N)$ equation of the tunnel bottom structure was obtained, as shown in Equation (6):

$$
\lg N=-3.83 S_{\max }-13.57 \Delta S+5.68(\text { Adjusted R-square }=0.92)
$$

where $\lg N=2$ indicates that the specimen can bear 1 million cycles without fracture.

Table 7. Fatigue lives of specimens.

\begin{tabular}{cccccc}
\hline \multirow{2}{*}{ Test Conditions } & \multirow{2}{*}{$\boldsymbol{S}_{\max } / \boldsymbol{\varepsilon}_{\max }$} & $\boldsymbol{\Delta} \boldsymbol{S} / \boldsymbol{\Delta} \boldsymbol{\varepsilon}$ & \multicolumn{3}{c}{ Fatigue Life } \\
\cline { 4 - 6 } & & & Test 1 & Test 2 & Test 3 \\
\hline Case 1 & $0.65 / 56 \times 10^{-6}$ & $0.056 / 16 \times 10^{-6}$ & $1,661,391$ & $>2,070,000$ & $>2,030,000$ \\
Case 2 & $0.70 / 68 \times 10^{-6}$ & $0.082 / 28 \times 10^{-6}$ & 937,982 & 863,045 & 424,988 \\
Case 3 & $0.75 / 74 \times 10^{-6}$ & $0.118 / 34 \times 10^{-6}$ & 142,565 & 171,412 & 182,940 \\
Case 4 & $0.80 / 85 \times 10^{-6}$ & $0.143 / 45 \times 10^{-6}$ & 62,348 & 73,915 & 107,242 \\
Case 5 & $0.60 / 52 \times 10^{-6}$ & $0.082 / 28 \times 10^{-6}$ & $>2,000,000$ & $>2,000,000$ & $>2,000,000$ \\
Case 6 & $0.65 / 56 \times 10^{-6}$ & $0.082 / 28 \times 10^{-6}$ & $1,873,947$ & $1,632,586$ & $1,836,432$ \\
Case 7 & $0.70 / 68 \times 10^{-6}$ & $0.082 / 28 \times 10^{-6}$ & 937,982 & 863,045 & 424,988 \\
Case 8 & $0.80 / 84 \times 10^{-6}$ & $0.082 / 28 \times 10^{-6}$ & 339,625 & 298,581 & 380,517 \\
\hline
\end{tabular}

Equation (6) is a two-parameter fatigue life equation with no corresponding $S-N$ curve in the two-dimensional (2D) plane graph, so two independent $S-N$ curves are drawn in Figure 11. Due to the lateral and bottom confinement, the fatigue lives of the specimens in this study were far longer than the results of related literature $[23,24]$.

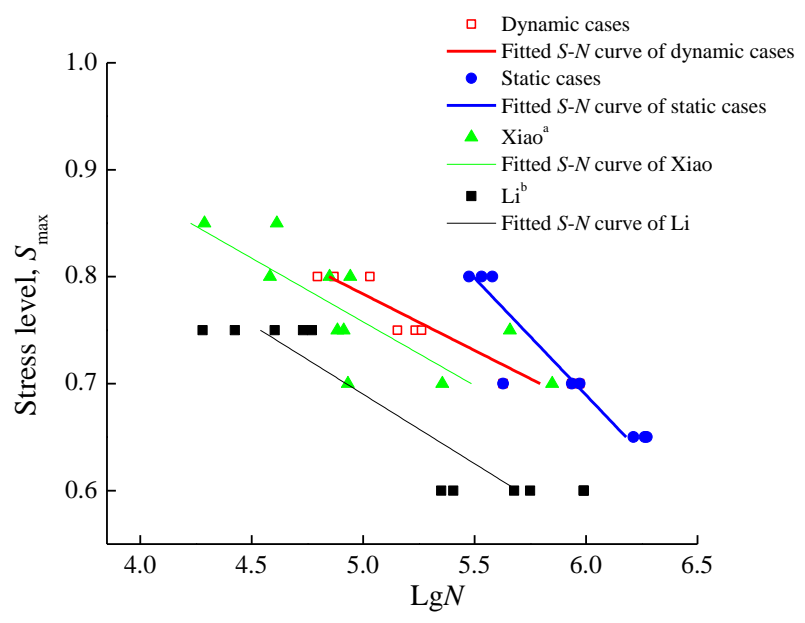

Figure 11. $S-N$ curves (based on a single parameter): ${ }^{a} 4$-point bending fatigue test in dry condition, span: $450 \mathrm{~mm}$, specimen size: $150 \times 150 \times 550 \mathrm{~mm}, f_{\mathrm{cu}}=57.5 \mathrm{MPa} .{ }^{\mathrm{b}}$ 3-point bending fatigue test in dry condition, span: $442 \mathrm{~mm}, R=0.1$, specimen size: $100 \times 100 \times 515 \mathrm{~mm}, f_{\mathrm{cu}}=51.7 \mathrm{MPa}$. 
When comparing the fatigue life of cases 1 and 6 and cases 4 and 8 , the fatigue lifespan of specimens appeared to be more sensitive to the dynamic stress than static stress, because, under the same maximum stress level, the fatigue life decreased sharply with the increase in dynamic stress.

In typical V-grade surrounding rock, under the impact of a $30 \mathrm{t}$ axle load train, fatigue failure would not occur in the tunnel invert within 2 million cycles, according to results of the tests and numerical simulation. The fatigue life decreased with increasing dynamic (train load) and static (rock pressure) loads.

The results also indicate that under the condition of $30 \mathrm{t}$ axle loads, any break in the inverted arch in the newly designed heavy haul railway tunnel structure could be attributed to the excessive pressure of surrounding rock or the bedrock defects, rather than the dynamic train load.

\section{Conclusions}

In this study, to examine the coupling effect of the surrounding rock pressure and $30 \mathrm{t}$ axle load trains, 3D numerical simulation and three-point bending fatigue tests were combined to investigate the fatigue performance of the bottom structures of the newly designed heavy haul railway tunnel. We drew the following:

1. The top center was the position vulnerable to fatigue in the tunnel invert of the new line, which experienced high static and low dynamic stresses. Its static maximum principal strain was $40.3 \times 10^{-6}$, which was caused by surrounding rock pressure, whereas the dynamic maximum principal strain caused by train load was $8.3 \times 10^{-6}$.

2. The tests results revealed that the fatigue life decreased as dynamic and static loads increased. Combined with the expression of the two-parameter $S-N$ curve, an evolution model was proposed to characterize the fatigue behavior of the tunnel invert specimens.

3. For the new line's tunnel invert structures, fatigue failure would not occur within 2 million cycles. Any invert fracture within the design service life could be attributed to geological reasons or bedrock defects, rather than fatigue failure caused by dynamic train load.

Author Contributions: Conceptualization, C.L.; methodology, C.L.; formal analysis, C.L. and N.L.; writing-original draft preparation, C.L.; writing—review and editing, C.L., L.P., M.L., C.S., and N.L.; supervision, L.P.; funding acquisition, M.L.

Funding: This project was funded by the National Natural Science Foundation of China (No. 51978669, U1734208) and the Natural Science Foundation of Hunan Province, China (No. 2018JJ3657), who are gratefully acknowledged. The experimental work described in this paper was completed in the Key Laboratory of Engineering Structure of Heavy Haul Railway in Central South University, China.

Conflicts of Interest: The authors declare no conflicts of interest.

\section{References}

1. Van Rickstal, F.; Van Gemert, D.; Bonheure, M. Fatigue testing of traffic tunnel panels. J. Perform. Constr. Fac. 1999, 13, 152-156. [CrossRef]

2. Wang, X.; Zhang, H.; Xie, W. Experimental Study of Dynamic Cumulative Damage Model for High Speed Railway Tunnel. Tunn. Constr. 2017, 37, 939-945. (In Chinese)

3. Han, J.; Liu, W.; Wang, S.; Geert, D.S.; Sun, W.; Liang, Y. Carbonation reaction and microstructural changes of metro-tunnel segment concrete coupled with static and fatigue load. J. Mater. Civ. Eng. 2017, 29, $1943-5533$. [CrossRef]

4. Qian, W.; Qi, T.; Yi, H.; Liang, X.; Jin, Z.; Lei, B.; Li, Y.; Li, Z. Evaluation of structural fatigue properties of metro tunnel by model test under dynamic load of high-speed railway. Tunn. Undergr. Sp. Tech. 2019, 93, 103099. [CrossRef]

5. Tian, B. Operation and development of railway heavy haul transport technology in the world. Roll. Stock 2015, 12, 10-19+5. 
6. Tian, Y. The Base Treatment Process with Grouting Resin in Datong-Qinhuangdao Railway Tunnels. Paper Collection of Heavy Haul Railway Transportation Technical Exchange; China Railway Society: Beijing, China, 2014; pp. $363-367$. (In Chinese)

7. Hu, Y. Current Status and Development Trend of Technology System for Railway Heavy Haul Transport in China. China Railw. Sci. 2015, 36, 1-10. (In Chinese)

8. Niu, Y. The Heavy Haul Railway Tunnel Diseases Mechanism and Remediation Technology Research. Master's Thesis, China Academy of Railway Sciences, Beijing, China, 2013. (In Chinese).

9. Huang, Y. Research on Monitoring System and Reinforcement Treatment of Heavy Haul Railway Long Tunnel's Bedding Diseases. Master's Thesis, Southwest Jiaotong University, Chengdu, China, 2015. (In Chinese).

10. Yin, C.; Fu, B.; Ma, W. Analysis on Dynamic Stress of Tunnel Structure under Heavy Haul Train. China Railw. Sci. 2013, 34, 47-52.

11. Xue, J. Analysis of the Influence of Tunnel Bottom Compactness on Structure Stress and Strengthening Measures under 30 t Axle Load Train. China Railw. Sci. 2015, 36, 90-95. (In Chinese)

12. Liu, N.; Peng, L.; Shi, C.; Lei, M. Experimental and model study on dynamic behaviour and fatigue damage of tunnel invert. Constr. Build. Mater. 2016, 126, 777-784. [CrossRef]

13. Zhang, Z.; Zeng, B.; Dai, C.; He, W. Study on Structural Service Performance of Heavy-Haul Railway Tunnel with Voided Base. Adv. Civ. Eng. 2018, 2018, 1-12. [CrossRef]

14. Nicholas, T.; Zuiker, J. On the use of the Goodman diagram for high cycle fatigue design. Int. J. Fract. 1996, 80, 219-235. [CrossRef]

15. TB 10003-2016. Code for Design of Railway Tunnel; China Railway Publishing House: Beijing, China, 2016. (In Chinese)

16. Chappell, B. Deformational response in discontinua. Int. J. Rock Mech. Sci. Geomech. 1979, 4, 377-390. [CrossRef]

17. Hernandez, Y.; Farfan, A.; De Assis, A. Three-dimensional analysis of excavation face stability of shallow tunnels. Tunn. Undergr. Sp. Tech. 2019, 92, 103062. [CrossRef]

18. Gu, Y.; Liu, J.; Du, Y. 3D consistent viscous-spring artificial boundary and viscous-spring boundary element. Gongcheng Lixue/Eng. Mech. 2007, 24, 31-37.

19. GB/T 50081-2002. Standard for Test Method of Mechanical Properties on Ordinary Concrete; China Architecture and Building Press: Beijing, China, 2003. (In Chinese)

20. Zhai, W.; Xia, H. Train-Track-Bridge of Train Track Bridge Dynamic Interaction: Theory and Engineering Application; Science Press: Beijing, China, 2011.

21. Klausen, D. Concrete strength and damage due to frequently repeated loading. Darmstadt 1978. (In German)

22. Oneschkow, N. Fatigue behaviour of high-strength concrete with respect to strain and stiffness. Int. J. Fatigue 2016, 87, 38-49. [CrossRef]

23. Xiao, J.; Li, H.; Yang, Z. Fatigue behavior of recycled aggregate concrete under compression and bending cyclic loadings. Constr. Build. Mater. 2013, 38, 681-688. [CrossRef]

24. Li, Y.; Che, H. A Study on the Cumulative Damage to Plain Concrete due to Flexural Fatigue. China Railw. Sci. 1998, 19, 52-59. (In Chinese)

(C) 2019 by the authors. Licensee MDPI, Basel, Switzerland. This article is an open access article distributed under the terms and conditions of the Creative Commons Attribution (CC BY) license (http://creativecommons.org/licenses/by/4.0/). 